GRASAS Y ACEITES 72 (3)

July-September 2021, e424

ISSN-L: 0017-3495

https://doi.org/10.3989/gya.0334201

\title{
Improving the oxidative stability of breadsticks with ginkgo (Ginkgo biloba) and ginseng (Panax ginseng) dried extracts
}

\author{
$₫$ K.S.M. Hammad, ®N.F.S. Morsy ${ }^{\bowtie}$ and $₫$ E.A. Abd El-Salam \\ Food Science Dep., Faculty of Agriculture, Cairo University, Egypt \\ ${ }^{\square}$ Corresponding author: nanafsm@yahoo.com
}

Submitted: 29 March 2020; Accepted: 27 July 2020; Published online: 17 September 2021

SUMMARY: Recently, there has been a growing interest in the use of natural antioxidants instead of synthetic ones. The aim of this work was to determine the effect of ginkgo and ginseng dried extracts as natural antioxidants on the stability of lipids in breadsticks over 55 days of storage at room temperature compared to butylated hydroxytoluene. Ginkgo and ginseng dried extracts were incorporated individually into breadstick formulae at levels of 0.5 and $1 \%$ to enhance its oxidative stability in storage. The increases in peroxide, $p$-anisidine and Totox values in the oil phase of the samples during storage were monitored. The changes in hydroperoxide, trans fatty acid and aldehyde contents were investigated by Fourier transform infrared spectroscopy. The sensory analysis was performed to evaluate the perceptible changes occurring during storage. The results indicated that the oxidation of oil in breadstick samples can be retarded by enriching the breadstick formula with dried ginseng extract at a $1 \%$ level.

KEYWORDS: Antioxidant; Breadstick; Ginkgo; Ginseng; Oxidative stability; Shelf-life

RESUMEN: Mejora de la estabilidad oxidativa de la barra de pan con extractos secos de ginkgo (Ginkgo biloba) y ginseng (Panax ginseng). En la actualidad existe un creciente interés por el uso de antioxidantes naturales en lugar de sintéticos. El objetivo de este trabajo fue determinar el efecto de extractos secos de ginkgo y ginseng como antioxidantes naturales sobre la estabilidad de los lípidos en barras de pan durante 55 días de almacenamiento a temperatura ambiente, en comparación con el butilhidroxitolueno. Los extractos secos de ginkgo y ginseng se incorporaron individualmente en la formulación de barra de pan a niveles de $0,5 \%$ y $1 \%$ para mejorar su estabilidad oxidativa durante el almacenamiento. Se siguió el aumento de los valores de peróxido, $p$-anisidina y Totox de la fase oleosa de las muestras durante el almacenamiento. Los cambios en los contenidos de hidroperóxido, ácidos grasos trans y aldehídos se investigaron mediante espectroscopía infrarroja por transformada de Fourier. El análisis sensorial se realizó para evaluar los cambios perceptibles ocurridos durante el almacenamiento. Los resultados indican que la oxidación del aceite en las muestras de barra de pan se puede retardar enriqueciendo la fórmula de barra de pan con extracto de ginseng seco al $1 \%$.

PALABRAS CLAVE: Antioxidante; Barra de pan; Estabilidad oxidativa; Gingko; Ginseng; Vida media

Citation/Cómo citar este artículo: Hammad KSM, Morsy NFS, Abd El-Salam EA. 2021. Improving the oxidative stability of breadsticks with ginkgo (Ginkgo biloba) and ginseng (Panax ginseng) dried extracts. Grasas Aceites 72 (3), e424. https://doi.org/10.3989/gya.0334201

Copyright: (C2021 CSIC. This is an open-access article distributed under the terms of the Creative Commons Attribution 4.0 International (CC BY 4.0) License. 


\section{INTRODUCTION}

A breadstick is a rolled-shaped crispy texture bakery product with a low moisture content, which is widely consumed all over the world. Maintaining the quality of bakery products, stored at room temperature, for a specific time is important from an economic point of view (Thanushree et al., 2017). Lipid oxidation and loss in crunchiness are the main causes of deterioration of the bakery products with low moisture and high fat contents, such as cookies and breadsticks (Calligaris et al., 2008; Caruso et al., 2017).

Unsaturated vegetable oils are used at different levels in the production of breadsticks (Difonzo et al., 2018). Extra virgin olive oil is used at $25 \%$ to prepare breadsticks. The type and level of fat in breadsticks are responsible for accelerated quality depletion. Increases in the degrees of fatty acids' unsaturation accelerates the rate of lipid oxidation. Antioxidants can be added into the formulae of food items to retard lipid oxidation and extend their shelflife (Alamprese et al., 2017).

Ginkgo (Ginkgo biloba, Family: Ginkgoaceae) is an ancient plant. Ginkgo leaves have been used as food and in traditional remedies for centuries (Wang and Zhang, 2019). The ginkgo leaf extract contains high amounts of flavonoids (24\%) and terpene lactones (6\%) (Wang et al., 2015). The antioxidant activity of ginkgo extract is attributed to its phenolic and flavonoid compounds (Sati et al., 2019). Kobus-Cisowska et al. (2014) inhibited the lipid oxidation of pork meatballs during 21 days of refrigerated storage by the addition of ginkgo lyophilized leaf extract to the meat batter at 500 $\mathrm{mg} / \mathrm{kg}$. Dipping silver pomfret (Pampus argenteus) fillets in ginkgo leaf extract at $2.5 \mathrm{mg} / \mathrm{mL}$ extended its shelf-life from 8 to 15 days during refrigerated storage in ice at $4{ }^{\circ} \mathrm{C}$ by suppressing lipid oxidation (Lan et al., 2018).

The roots of ginseng (Panax ginseng, Family: Araliaceae) are well known for their high contents in saponins, ginsenosides, phenolic compounds, and carotenoids (Riaz et al., 2019). Ginseng products including ginseng extract have been approved for use as a food or food ingredient, according to the Codex Standard (321-2015). Supplementing milk or yogurt with ginseng extract at $2 \%$ significantly increased the DPPH radical scavenging activity of the product (Park et al., 2018).
There are only a few studies available concerning the shelf-life of breadsticks (Calligaris et al., 2008; Alamprese et al., 2017; Barbieri et al., 2018). To date, no study using ginkgo or ginseng dried extracts as natural antioxidants to extend the shelf-life of bakery products has been reported. Thus, the aim of this study was to investigate the effectiveness of ginkgo and ginseng dried extracts on the oxidative stability of breadsticks during storage at room temperature.

\section{MATERIALS AND METHODS}

\subsection{Materials}

Refined sunflower oil (without added antioxidants) was obtained from Ajwa for Food Industries Co., Egypt. Ginkgo biloba dried leaf extract powder was procured from Changsha Huakang Biotechnology Development Co., LTD (Changsha, Hunan, China). Asian Panax ginseng, dried root extract was provided by Dalian Tianshan Industrial Co., LTD (Dalian, China). Ginsenoside standards (Rb1, Rb2, Rc, Rd, $\mathrm{Re}, \mathrm{Rf}$, and $\mathrm{Rg} 1$ ) were obtained from Extrasynthese (Lyon, France). Butylated hydroxy toluene (BHT), Gallic acid and Folin Ciocalteu reagent were procured from Sigma Aldrich, USA. Wheat flour, type 55 (72\% extraction rate), Five Star Flour Mills Company, Suez, Egypt, and instant dry yeast (Lesaffre, Egypt) were purchased from a local market (Cairo, Egypt).

\subsection{Preparation of breadsticks}

Six breadstick formulae were prepared using 500 $\mathrm{g}$ wheat flour, $208.5 \mathrm{~mL}$ water, $50 \mathrm{~g}$ sugar, $3.5 \mathrm{~g}$ salt, $13.5 \mathrm{~g}$ yeast and $100 \mathrm{~mL}$ sunflower oil. Based on the wheat flour weight, the investigated formulae were: (1) without antioxidant (control), (2) BHT $(0.02 \%)$, (3) Ginkgo extract $(0.5 \%)$, (4) Ginkgo extract (1\%), (5) Ginseng extract (0.5\%), and (6) Ginseng extract $(1 \%)$. Investigated extracts and BHT were completely dissolved in the oil phase using a vortex mixer for $5 \mathrm{~min}$. All of the previous ingredients were mixed at slow speed for $2 \mathrm{~min}$, then at medium speed for 10 min using a kitchen mixer (Moulinex, Supermix 150, France). The dough was left to rest for $10 \mathrm{~min}$. After that, the dough was hand-rolled to form long cylindrical strips. The fermentation was performed at $35^{\circ} \mathrm{C}$ and $80 \%$ relative humidity for 40 min. Baking was carried out at $170^{\circ} \mathrm{C}$ for $35 \mathrm{~min}$ in a rotary oven fitted with a fermentation room (SHOF, Jeddah, Saudi Arabia). The breadstick samples were 
allowed to cool for $2 \mathrm{~h}$. Breadstick samples made from each formula were packed ( $200 \mathrm{~g}$ each pack) in plastic bags before storage at $25^{\circ} \mathrm{C}$.

\subsection{Extraction of oil from breadstick samples}

A breadstick sample (20 g) was ground into a fine powder using a laboratory blender. The oil fraction of the ground breadstick sample was extracted using diethyl ether at a ratio of $1: 10(\mathrm{w} / \mathrm{v})$ with magnetic stirring for $1 \mathrm{~h}$ at room temperature followed by filtration through filter paper (Whatman No. 1). The solvent was evaporated under vacuum at $30{ }^{\circ} \mathrm{C}$ by a rotary evaporator. The extracted oil was stored at $5{ }^{\circ} \mathrm{C}$. Analyses were carried out after processing $(0$, 10 days of storage) and periodically every 15 days. The experiment was terminated when the peroxide value of the oil phase of either ginkgo or ginseng breadstick samples in both concentrations reached or exceeded 10 meq $\mathrm{O}_{2} / \mathrm{kg}$ oil (limit of acceptability as reported by Calligaris et al., 2008).

2.4. Determination of total phenolic contents in the ginkgo and ginseng extracts

The total phenolic contents (TPC) in the ginkgo and ginseng extracts were determined by Folin Ciocalteu's colorimetric method (Arnous et al., 2002). An aliquot of sample $(10 \mu \mathrm{L})$ was mixed with $50 \mu \mathrm{L}$ of FolinCiocalteu reagent and $790 \mu \mathrm{L}$ of distilled water using a vortex mixer. The mixture was allowed to stand for $1 \mathrm{~min}$ for reaction. Afterwards, the mixture was neutralized by $150 \mu \mathrm{L}$ sodium carbonate $(20 \%)$ and left to stand in the dark for $2 \mathrm{~h}$. The absorbance of the samples was determined using a Shimadzu UV-2450 Spectrophotometer, Japan, at $750 \mathrm{~nm}$. Gallic acid was used as a standard. Results were expressed as mg gallic acid equivalents (GAE)/g dry extract.

\subsection{Determination of total phenolic content in pre- pared breadsticks}

The determination of TPC in the freshly prepared breadstick samples was carried out according to Bhat et al. (2019). Crushed breadsticks $(0.5 \mathrm{~g})$ were suspended in $25 \mathrm{~mL}$ of acidified methanol $(\mathrm{HCl} / \mathrm{methanol} /$ water, 1:80:10, v/v/v) for $2 \mathrm{~h}$. After centrifugation at $2000 \mathrm{~g}$ for $10 \mathrm{~min}, 200 \mu \mathrm{L}$ of the supernatant were mixed with $1.5 \mathrm{~mL}$ of the diluted (10 fold) Folin-Ciocalteu reagent using a vortex mixer. The mixture was allowed to equilibrate for 5 min and neutralized with $1.5 \mathrm{~mL}$ of sodium carbonate solution $(60 \mathrm{~g} / \mathrm{L})$. The samples were incubated for 90 min at room temperature $\left(25^{\circ} \mathrm{C}\right)$. The absorbance of the samples was determined as above mentioned.

2.6. High performance liquid chromatography (HPLC) analysis of phenolic compounds in ginkgo extract and ginsenosides in ginseng extract

The determination of phenolic compounds in the ginkgo extract was performed by Agilent 1260 series HPLC (Agilent Technologies Co., CA, USA). The separation was carried out using an Agilent Zorbax Eclipse XDB-C18 column (4.6 mm x $250 \mathrm{~mm}, 5$ $\mu \mathrm{m}$ particle size). The mobile phase consisted of water containing $1 \%$ acetic acid (A) and acetonitrile (B) and the flow rate was maintained at $1 \mathrm{~mL} / \mathrm{min}$. The mobile phase was programmed consecutively in a linear gradient as follows: $0-5 \min (80 \% \mathrm{~A})$; $5-8 \min (40 \% \mathrm{~A}) ; 8-12 \min (50 \% \mathrm{~A}) ; 12-25 \mathrm{~min}$ $(80 \% \mathrm{~A})$. The detector was monitored at $284 \mathrm{~nm}$. The injection volume was $10 \mu \mathrm{L}$. The column temperature was maintained at $35^{\circ} \mathrm{C}$. The peaks were identified by retention time after matching with authentic standards. The linear calibration curve of the standards was used for quantification.

The ginsenosides in the ginseng extract were analyzed using a Shimadzu LC-20 (Prominence) connected to an ultraviolet detector (Hitachi, Tokyo, Japan) at $203 \mathrm{~nm}$. The ginseng extract sample was dissolved in 30\% methanol by sonication and filtered ( $0.45 \mu \mathrm{m}$, Acrodisk). The separation was performed on an Altima HP C $\mathrm{C}_{18} \mathrm{HL}$ column (150 mm x $4.6 \mathrm{~mm}$ i.d., $3 \mu \mathrm{m}$ ). The analysis was carried out with a binary gradient elution using (A) water and (B) acetonitrile as the mobile phase, according to the method of $\mathrm{Li}$ and Fitzloff (2002). The gradient elution program was as follows: $0-33 \mathrm{~min}, 19-35 \% \mathrm{~B}$; $33-33.6 \mathrm{~min}, 35-80 \%$ B; $33.6-37 \mathrm{~min}, 80-19 \%$ B. The flow rate was $1.5 \mathrm{~mL} /$ $\mathrm{min}$. The temperature of the analytical column was 30 ${ }^{\circ} \mathrm{C}$. The identification of ginsenosides was carried out using the reference standards. The quantification was performed according to the area normalization method.

\subsection{Quality characteristics of oil samples extracted from prepared breadsticks}

\subsubsection{Peroxide value}

The peroxide value (PV) of the samples was determined according to AOCS (2009) methods. 
The results were expressed as the average of three measurements in meq $\mathrm{O}_{2} / \mathrm{kg}$ oil. The analysis was carried out in triplicate. Samples with PV over 10 meq $\mathrm{O}_{2} / \mathrm{kg}$ oil were excluded and not subjected to further analysis.

\subsection{2. p-Anisidine value}

The $p$-anisidine value $(p-\mathrm{AnV})$ was determined according to the AOCS (2009) method using a Shimadzu UV-2450 Spectrophotometer, Japan at $350 \mathrm{~nm}$ against a blank of isooctane. $p$-AnV was calculated by the following formula:

$$
p-\mathrm{AnV}=25(1.2 A s-A b) / m
$$

where: $\mathrm{Ab}$ is the absorbance for sample dissolved in isooctane, As is the absorbance for the oil solution after reaction with $p-\mathrm{AnV}$, and $\mathrm{m}$ is the mass of oil in $25 \mathrm{~mL}$ isooctane. The analysis was done in triplicate.

\subsubsection{Totox value}

The level of total oxidation was calculated from the following equation according to AOCS (2009) method:

$$
\text { Totox }=2 \mathrm{PV}+p-\mathrm{AnV}
$$

\subsection{Spectral characteristics of oil extracted from breadsticks}

\subsubsection{IR spectroscopy}

Infrared absorption spectra were recorded in the mid IR region of $4000-400 \mathrm{~cm}^{-1}$ for potassium bromide ( $\mathrm{KBr}$ ) disks of oil extracted from breadstick samples $(\sim 2 \mu \mathrm{L})$ to monitor changes related to the oxidative process with an FTIR spectrometer (JASCO 6100, Japan). The spectrometer was connected to a computer using Windows XP Professional software to manipulate the spectra.

\subsection{Sensory evaluation}

The sensory assessment was carried out on breadstick samples prepared with and without different levels of ginkgo leaf or ginseng root extracts compared to those formulated with BHT. Ten staff members of the Food Science Department (six females and four males), aged between 25 and
35 years, were selected for sensory evaluation. The sensory attributes (odor, taste and texture) were evaluated. The scores for each parameter ranged from one to a maximum of nine, where one indicated poor quality, and nine represented the best quality.

\subsection{Statistical analyses}

The chemical and sensory analyses were carried out in triplicate and the results presented are the average of the obtained values \pm standard deviation. The data were submitted to analysis of variance (ANOVA) and the Tukey's test. A bivariate analysis of the data was carried out by Pearson's correlation test. A value of $\mathrm{P}<0.05$ was considered statistically significant. Analyses were performed using XLSTAT software.

\section{RESULTS AND DISCUSSION}

\subsection{Chemical composition of ginkgo and ginseng extracts}

The total polyphenol content of the dried ginkgo ethanol extract was $92.3 \pm 0.3 \mathrm{mg} \mathrm{GAE} / \mathrm{g}$. Pereira et al. (2013) reported that the phenolic contents of aqueous and methanol extracts of the G. biloba dry leaves were 61.58 and $129.5 \mathrm{mg} \mathrm{GAE} / \mathrm{g}$, respectively. The HPLC profile of the dried ginkgo extract (Figure 1a) contained ellagic acid $(490.46 \mu \mathrm{g} / \mathrm{g})$, gallic acid $(223.31 \mu \mathrm{g} / \mathrm{g})$, resveratrol $(181.24 \mu \mathrm{g} / \mathrm{g}), p$-hydroxy benzoic acid $(112.56 \mu \mathrm{g} / \mathrm{g})$ followed by myricetin $(58.74 \mu \mathrm{g} / \mathrm{g})$, quercetin $(27.55 \mu \mathrm{g} / \mathrm{g})$ and o-coumaric $\operatorname{acid}(23.99 \mu \mathrm{g} / \mathrm{g})$. The other components were quinol $(15.71 \mu \mathrm{g} / \mathrm{g})$, kampherol $(12.14 \mu \mathrm{g} / \mathrm{g})$, syringic acid $(8.2 \mu \mathrm{g} / \mathrm{g})$ and vanillic acid $(7.13 \mu \mathrm{g} / \mathrm{g})$.

According to HPLC analysis, Re (38.03\%), Rd $(23.12 \%)$ and $\operatorname{Rg} 1(10.69 \%)$ represented the major identified ginsenosides of the investigated ginseng extract (Figure 1b). The other identified ginsenosides were $\mathrm{Rb} 1$ (9.47\%), Rb2 (6.90\%), Rf (6.43\%) and Rc (5.37\%). Ginsenosides are considered the main active components of Panax ginseng extract (Chen et al., 2017). A quantitative analysis was carried out on 45 Asian and American ginseng samples by HPLC. The aim was to correlate ginsenoside contents with morphological features of the ginseng plant roots to provide a scientific basis for evaluating the quality of Asian and American ginsengs through morphological features. The analysis indicated that many of the Asian ginseng samples contained ginsenoside profiles similar to the one found in this study. 
a

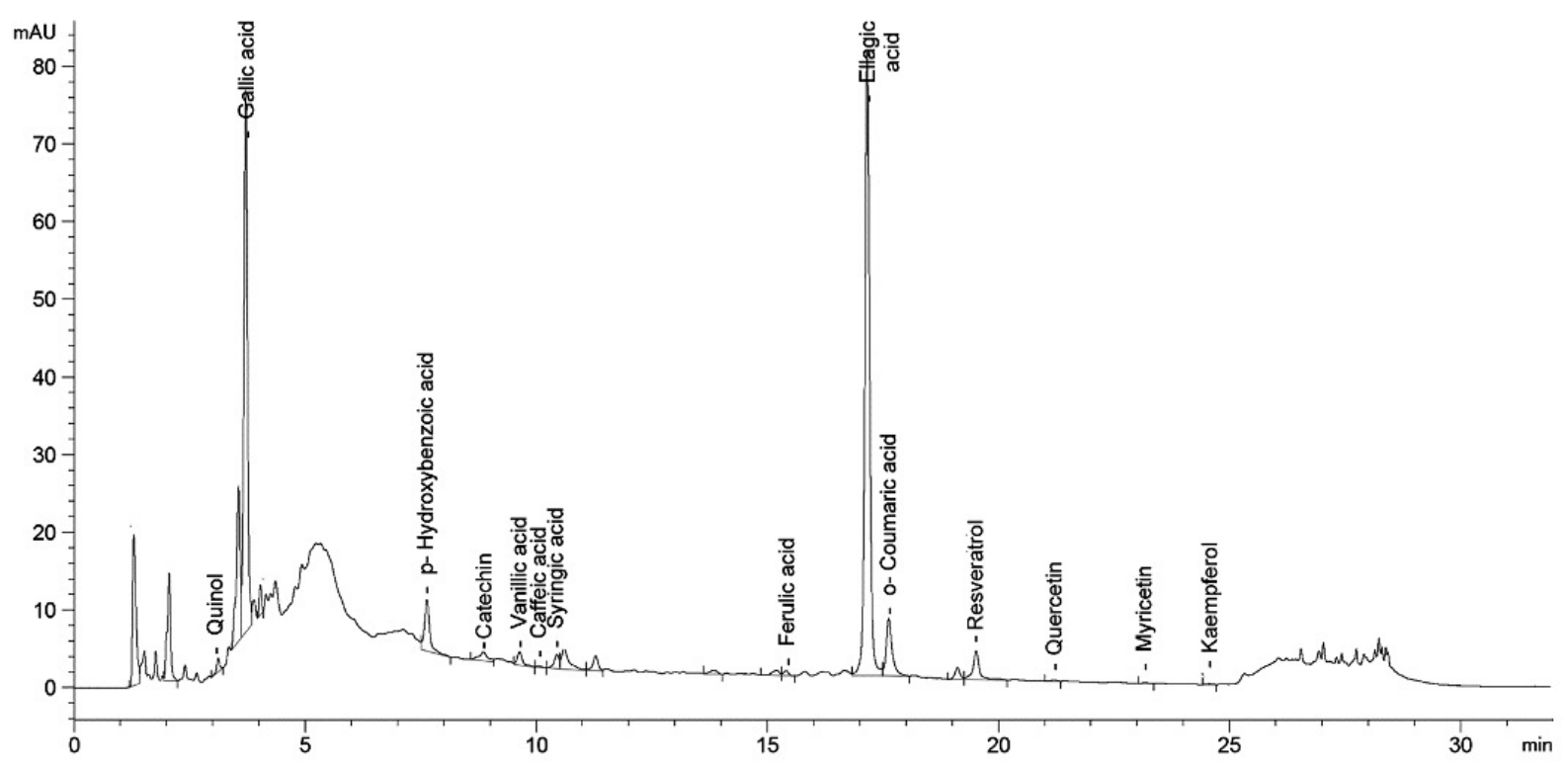

b

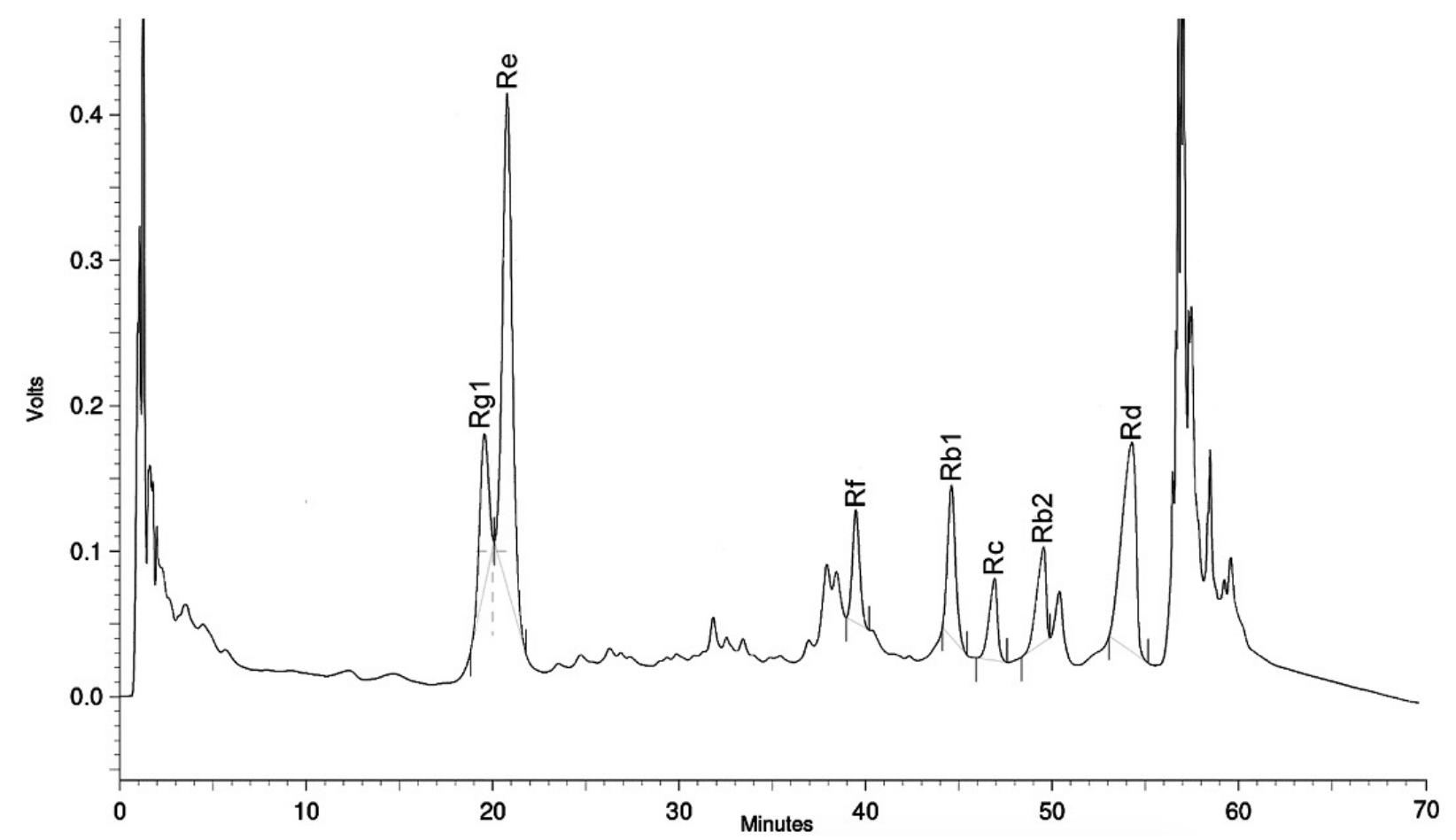

FIGURE 1. HPLC chromatograms of polyphenols of gingko extract (a) and ginsenosides of ginseng extract (b). The values refer to a single determination

In addition, the TPC of the dried ginseng extract was found to be $0.225 \pm 0.01 \mathrm{mg} \mathrm{GAE} / \mathrm{g}$. Hwang et al. (2014) found that the TPC of the ginseng root extract was $0.43 \mathrm{mg} \mathrm{GAE} / \mathrm{g}$.
Results indicated that the polyphenol content of ginkgo $1 \%$ breadstick samples $(0.412 \pm 0.018 \mathrm{mg}$ GAE/g) was significantly $(\mathrm{P}<0.05)$ higher than other samples. Ginkgo $0.5 \%$, ginseng $1 \%$ and ginseng $0.5 \%$ 
breadstick samples contained $0.351 \pm 0.019,0.338 \pm$ 0.02 and $0.316 \pm 0.02 \mathrm{mg} \mathrm{GAE} / \mathrm{g}$, respectively. They were not significantly $(\mathrm{P}>0.05)$ different from each other. The lowest TPC was recorded for the control $(0.288 \pm 0.007 \mathrm{mg} \mathrm{GAE} / \mathrm{g})$ and BHT $(0.291 \pm 0.018$ mg GAE/g) breadstick samples. No significant (P $>0.05$ ) difference was observed between the TPC of the control, BHT and ginseng $0.5 \%$ breadstick samples. Reis and Abu-Ghannam (2014) found that TPC of breadsticks (control sample) was about $0.1 \mathrm{mg} \mathrm{GAE} / \mathrm{g}$. On the other hand, the TPC of "crostini" reached $2.3 \mathrm{mg} \mathrm{GAE} / \mathrm{g}$. This type of dried bakery food was prepared with extra virgin olive oil at a level of 10\% (Niccolai et al., 2019). The effect of baking on the TPC of the baked products is dependent on the type of phenolic compounds and baking conditions (Abdel-Aal and Rabalski, 2013). They reported that baking caused an apparent increase in free phenolic acids in bread due to the degradation of conjugated polyphenolic compounds.

\subsection{Evaluation of the chemical oxidation indices of oil extracted from breadstick}

The peroxide value (PV) was used as an indicator to follow up the oxidation state of the oil in prepared breadsticks. Calligaris et al., (2008) reported that peroxide value is a good index of the quality decay of breadsticks during their shelf-life. Figure 2 shows the PV of the oil extracted from the breadsticks after baking and during storage.

Immediately after baking, the investigated samples showed a PV of between $4.07 \pm 0.23$ and $7.37 \pm 0.15 \mathrm{meq} \mathrm{O}_{2} / \mathrm{kg}$ oil. The samples with ginseng extract at a $1 \%$ level or BHT showed the lowest content of peroxides at zero storage time. The baking process initiated the oxidation process, which was very fast in the control sample. After 25 days of storage at room temperature $\left(25^{\circ} \mathrm{C}\right)$, the PV exceeded $10 \mathrm{meq} \mathrm{O}_{2} / \mathrm{kg}$ oil in the control sample (14.93 meq $\mathrm{O}_{2} / \mathrm{kg}$ oil), and in the sample prepared with $0.5 \%$ ginkgo extract ( 11.9 meq $\mathrm{O}_{2} / \mathrm{kg}$ oil).

Breadstick samples with ginseng extract at the $1 \%$ level, showed PV lower than the BHT ones throughout the storage period. The incorporation of ginkgo or ginseng extracts at $1 \%$ extended the shelf-life of the breadsticks from $<25$ days to 55 days. This indicated the protective effect of ginkgo and ginseng extracts against oil oxidation in breadsticks. Alamprese et al., (2017) found that the PV of the breadstick samples
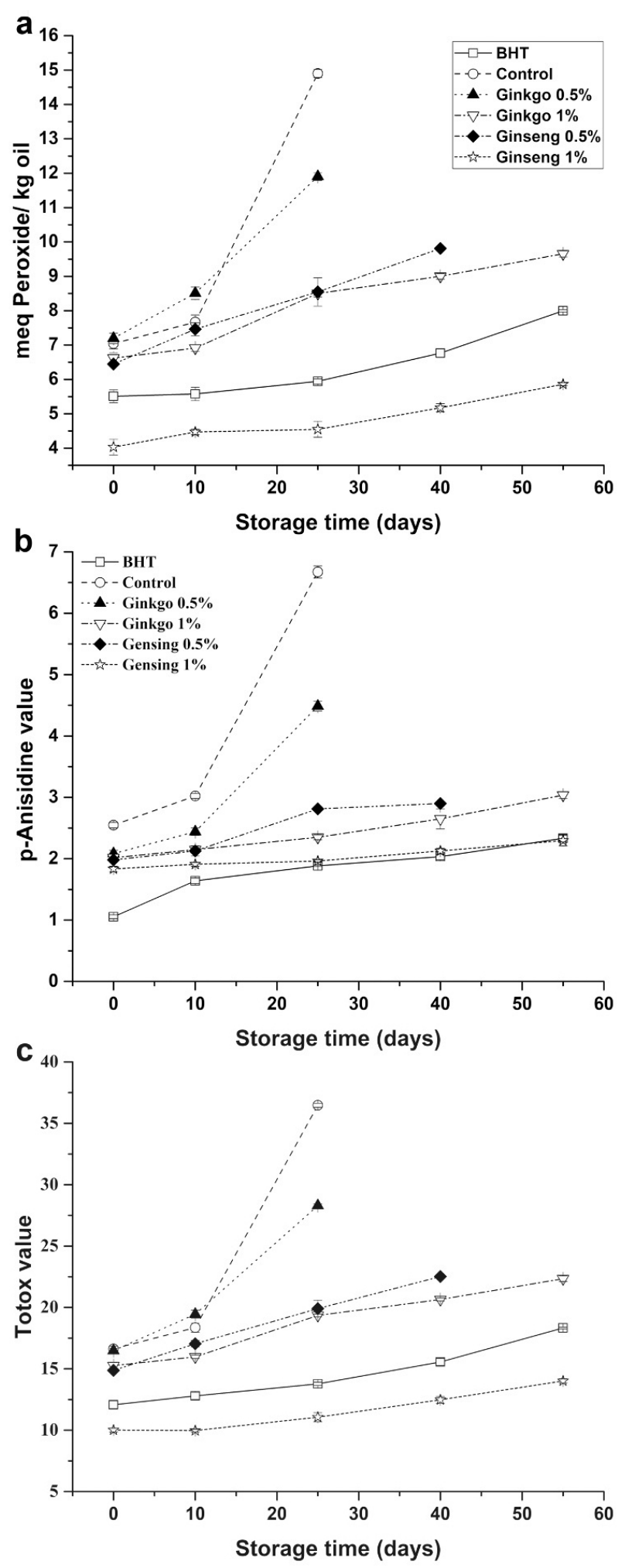

FIGURE 2. Progression of oil oxidation during the storage of the breadstick samples at $25^{\circ} \mathrm{C}$. Peroxide value (a), $p$-anisidine value (b) and Totox value (c). Values are expressed as means \pm standard deviation $(n=3)$. Data were analyzed using one-way analysis of variance (ANOVA) and Tukey's test. Samples with peroxide values higher than 10 meq $\mathrm{O}_{2} / \mathrm{Kg}$ were rejected and excluded from analysis 
prepared with only $3.2 \%$ olive oil exceeded $10 \mathrm{meq}$ $\mathrm{O}_{2} / \mathrm{kg}$ oil after 60 days of storage at $27^{\circ} \mathrm{C}$. Calligaris et al., (2008) found that the consumer acceptability of the breadsticks progressively decreased with the increase in PV value to higher than 10 meq $\mathrm{O}_{2} / \mathrm{kg}$ oil. Hydroperoxides decomposed to secondary oxidation products that could be detected by the $p$-anisidine test (Barbieri et al., 2018).

Peroxide and $p$-AnV values help to assess the oxidative degradation of lipids in lipid-containing food (Kozłowska et al., 2019). Mustac et al. (2020) reported that a product is considered acceptable if the $p$-AnV value is less than 10 . The $p$-Anisidine value of the control and $0.5 \%$ ginkgo breadstick samples reached high levels $(>4)$ after 25 days of storage at room temperature. On the other hand, the $p-\mathrm{AnV}$ value of breadstick samples prepared with ginkgo or ginseng extracts at $1 \%$ or $0.02 \%$ BHT did not exceed 2.5 at the end of storage. Caruso et al. (2017) reported that the $p$-AnV value of freshly prepared breadstick samples with $13.3 \%$ olive oil was 5.89 .

The combination of PV with $p-\mathrm{AnV}$ indicates the oxidation state (total oxidation value, Totox value) of oils. The Totox value must be equal or below $19.5 \mathrm{meq} / \mathrm{kg}$ (Esfarjani et al., 2019). The totox value of the investigated samples showed the same trend as those of the PV and $p$-AnV values. The Totox value of the control and $0.5 \%$ ginkgo breadstick samples was the highest ( $\sim 20 \mathrm{meq} / \mathrm{kg}$ ) after 10 days of storage.

Among all the investigated breadstick samples, $1 \%$ ginseng and $0.02 \%$ BHT samples had the lowest Totox value $(<17 \mathrm{meq} / \mathrm{kg})$ after 55 days of storage at room temperature.

The progressive increase in PV in the stored breadstick samples due to lipid oxidation is associated with the development of an increase in $p-\mathrm{AnV}$ and Totox values. From the results, the ginseng extract at a concentration of $1 \%$ has a greater antioxidant effect than that of $0.02 \%$ BHT. Phenolics are responsible for the antioxidant activity of ginkgo extract (Pereira et al., 2013) while the antioxidant activity of ginseng extract is attributed to the identified ginsenosides (Rb1, Rg1, Rc, Rb2, and Rd) as reported by Chien et al., (2016).

\subsection{Evaluation of the FTIR spectrum of breadstick oil}

The FTIR spectra of the oil extracted from the fresh and stored breadstick samples were recorded in the range of $4000-400 \mathrm{~cm}^{-1}$ and illustrated in Figure 3.
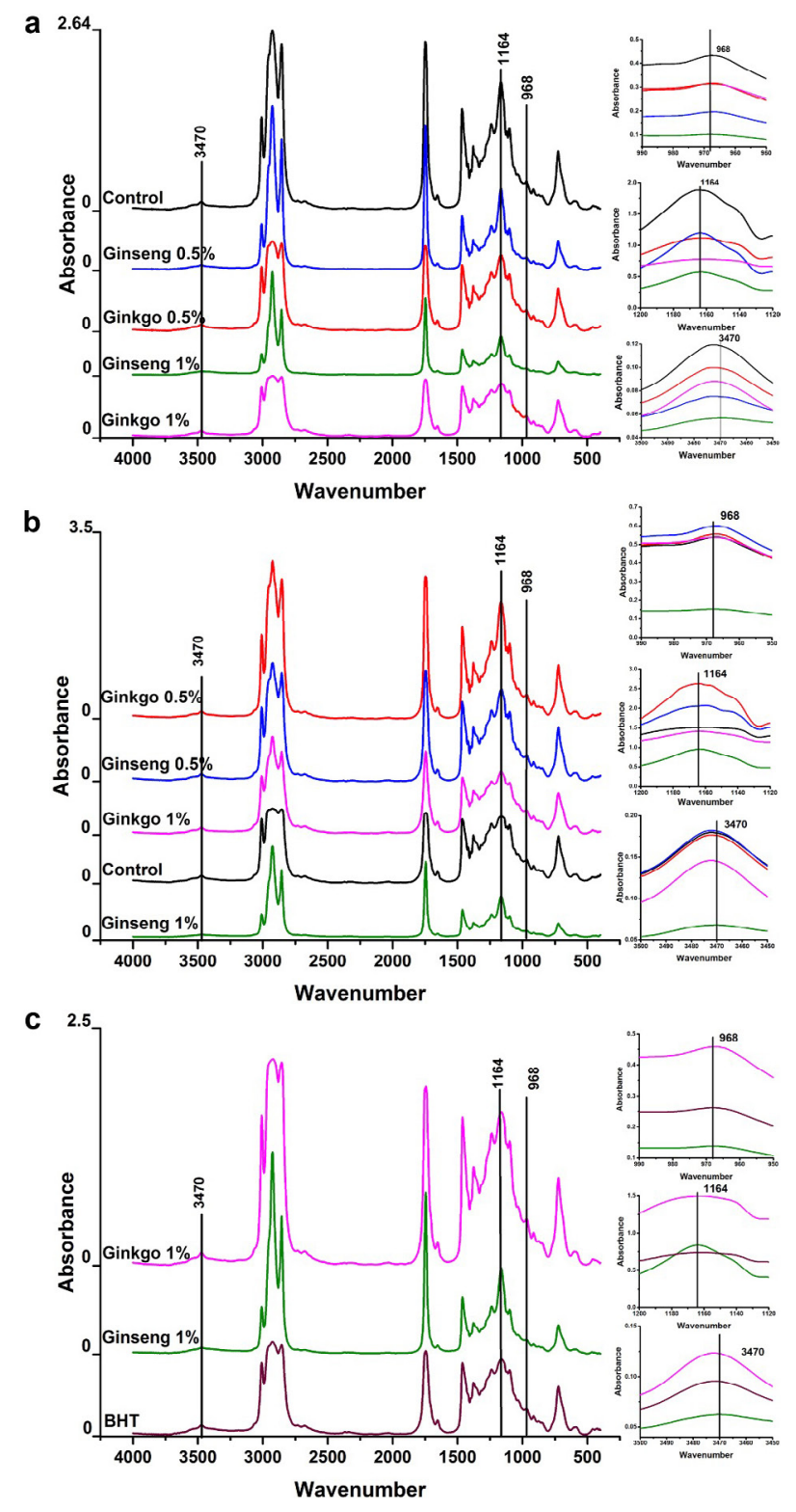

FigURE 3. Time-course spectra of sunflower oil in breadsticks during storage on IR, illustrating the development of hydroperoxides $\left(3470 \mathrm{~cm}^{-1}\right)$, aldehydes $\left(1164 \mathrm{~cm}^{-1}\right)$ and trans double bonds $\left(968 \mathrm{~cm}^{-1}\right)$ over time $(0,25$ and 55 days, correspond to labels a, b and c, respectively). Samples with peroxide values higher than 10 meq $\mathrm{O}_{2} / \mathrm{Kg}$ were rejected and excluded from analysis. The values refer to a single determination

These spectra appear to be similar and show the typical characteristic of absorption peaks for triglycerides (wave number $1746 \mathrm{~cm}^{-1}$ represented the ester functional group of the triglycerides) as shown by Klaypradit et al. (2011). In terms of oxidation analysis, the IR spectral bands of the functional groups hydroperoxide $\left(3470 \mathrm{~cm}^{-1}\right)$, carbonyl group 
$\left(1164 \mathrm{~cm}^{-1}\right)$ and trans double bond $\left(968 \mathrm{~cm}^{-1}\right)$ were used to assess the quality of the oil as reported by Daoud et al., (2019). The absorption peak at 3470 $\mathrm{cm}^{-1}$ increased progressively in the control samples and in the samples prepared with ginkgo or ginseng extracts at $0.5 \%$ during the first 25 days of storage at room temperature. The addition of ginkgo or ginseng extracts at $1 \%$ or $0.02 \%$ BHT in the formula of the breadsticks kept the band at $3470 \mathrm{~cm}^{-1}$ after 55 days, which is similar to the pattern of the control sample at zero storage time.

As the oxidation processes proceed, the formation of the aldehyde functional group is represented by an increase of the absorbance at $1164 \mathrm{~cm}^{-1}$ according to Daoud et al., (2019). The control sample recorded the highest absorbance at $1164 \mathrm{~cm}^{-1}$ at the beginning of storage. The level of aldehydes in samples prepared with ginkgo or ginseng extracts at the $0.5 \%$ level was similar at zero time storage and progressively increased after 25 days of storage. The lowest absorbance at this wavenumber was recorded for the samples containing $1 \%$ ginseng during storage.

The absorbance at the wavenumber $968 \mathrm{~cm}^{-1}$ appears as a weak band. An increase in the absorbance at this band is associated with the formation of trans double bonds that arose in the course of oxidation as reported by Daoud et al. (2019). At zero storage time, the highest absorbance at this wavenumber was observed for the control sample. The oil in the breadstick sample prepared with ginseng extract at $1 \%$ recorded the lowest peak intensity at this band compared to other samples throughout the storage period.

The oil in the breadsticks prepared with $1 \%$ ginseng showed the lowest absorbance in all the investigated spectral bands in comparison to all other samples throughout the storage period.

\subsection{Sensory characteristics of breadsticks}

The shelf-life of a food item depends mainly on its sensory characteristics and marketability (Alamprese et al., 2017). Lipid oxidation exerts rancidity and deteriorative changes in its odor and taste. Figure 4 shows the results of the sensory analysis of the tested samples.

No significant differences $(\mathrm{P}>0.05)$ were found in the sensory attributes of the breadstick samples at zero storage time (Figure $4 \mathrm{a}$ ). The addition of ginkgo or ginseng extracts at the $1 \%$ level did not significantly $(\mathrm{P}>0.05)$ affect the perception of baked odor or taste and texture attributes. The odor, taste and texture scores for the samples prepared with ginkgo or ginseng extracts at the $1 \%$ level and stored for 10 and 25 days were not significantly different $(\mathrm{P}>0.05)$ from those of the BHT samples (Figure $4 \mathrm{~b}$ and $4 \mathrm{c})$. The perceived odor and taste of the samples prepared with a low level $(0.5 \%)$ of ginkgo, ginseng or extracts were recognized as significantly less desirable $(\mathrm{P}<0.05)$ than those prepared with the same extract at a higher level (1\%) after 25 days of storage (Figure 4c). The same trend was also noticed in the ginseng samples stored for 40 and 55 days. The sensory characteristics of the control and $0.5 \%$ ginkgo samples were not significantly different $(\mathrm{P}$ $>0.05$ ) after 25 days of storage. Moreover, both samples recorded significantly $(\mathrm{P}<0.05)$ the lowest scores compared to those of the other samples (Figure $4 \mathrm{c})$. On the other hand, the odor and taste sensory attributes of the $1 \%$ ginseng and BHT samples were not significantly different $(\mathrm{P}>0.05)$ after 40 and 55 days of storage (Figure $4 \mathrm{~d}$ and $4 \mathrm{e}$ ). Meanwhile, the odor and taste scores for both breadstick samples were significantly higher $(\mathrm{P}<0.05)$ than those of the $1 \%$ ginkgo and $0.5 \%$ ginseng samples.

The crispiness of the breadstick samples prepared with ginseng extract at $0.5 \%$ or $1 \%$ of either ginkgo or ginseng extracts was not significantly different ( $\mathrm{P}$ $>0.05$ ) from that of the BHT sample after 40 and 55 days of storage (Figure $4 \mathrm{~d}$ and $4 \mathrm{e}$ ). It could be noticed that the preparation of breadsticks with $1 \%$ ginseng extract extended their shelf-life to 55 days at room temperature.

The correlation between oxidative indices and the sensory attributes (odor, taste and texture) using Pearson's correlation is shown in Table 1.

The results in Table 1 show an inverse correlation $(\mathrm{r}<-0.74, \mathrm{P}<0.01)$ between the oxidative chemical indices and the good odor, taste and texture scores. Loss in crispness is negatively correlated with the oxidation products in the oil phase of the breadstick samples. This result is consistent with that reported by Caruso et al. (2017). The results revealed significant $(\mathrm{P}<0.01)$ positive $(\mathrm{r}>0.89)$ correlations among the oxidative chemical indices. The same statistical trend $(r>0.93)$ was found between odor and taste sensory attributes.

In addition, it has previously been shown by Barbieri et al. (2018) that the secondary products 

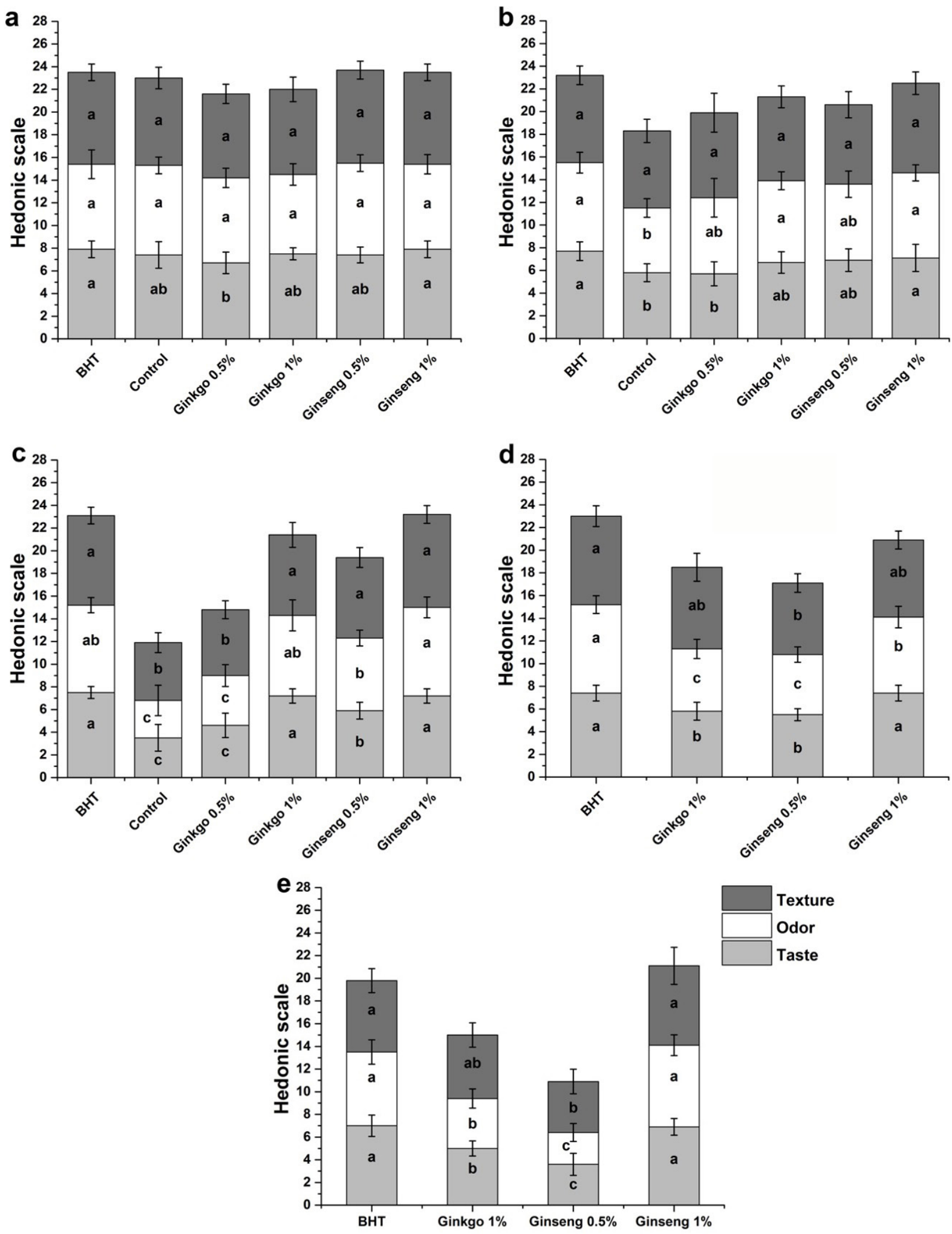

FIGURE 4. Averages of sensory attribute consumer' acceptance ( 9 point hedonic scale, $1=$ poor quality, $9=$ best quality) of fresh breadstick samples (a) and after storage at room temperature for 10 days (b), 25 days (c), 40 days (d) and 55 days (e). Significant differences among the means $(n=3)$ were determined by analysis of variance and Tukey's test. Sensory attribute scores sharing the same letter are not significantly different $(\mathrm{P}>0.05)$. The error bars show \pm standard deviation values. Samples with peroxide values higher than $10 \mathrm{meq} \mathrm{O}_{2} /$ $\mathrm{Kg}$ were rejected and excluded from analysis 
10 - K.S.M. Hammad, N.F.S. Morsy and E.A. Abd El-Salam

TABLE 1. Pearson's correlation analyses between oxidation indices, taste, odor and texture of breadstick samples

\begin{tabular}{lcccccc}
\hline \multirow{2}{*}{ Variables } & \multicolumn{5}{c}{ Correlation coefficient (r) } \\
\cline { 2 - 6 } & Taste & Odor & Texture & Peroxide value & $\rho$-Anisidine value & Totox \\
\hline Taste & 1 & $0.9352^{* *}$ & $0.7804^{* *}$ & $-0.9504^{* *}$ & $-0.8403^{* *}$ & $-0.9443^{* *}$ \\
Odor & $0.9352^{* *}$ & 1 & $0.6246^{* *}$ & $-0.8950^{* *}$ & $-0.7893^{* *}$ & $-0.8904^{* *}$ \\
Texture & $0.7804^{* *}$ & $0.6246^{* *}$ & 1 & $-0.7741^{* *}$ & $-0.7432^{* *}$ & $-0.7761^{* *}$ \\
Peroxide value & $-0.9504^{* *}$ & $-0.8950^{* *}$ & $-0.7741^{* *}$ & 1 & $0.8945^{* *}$ & $0.9967^{* *}$ \\
$\rho$-Anisidine value & $-0.8403^{* *}$ & $-0.7893^{* *}$ & $-0.7432^{* *}$ & $0.8945^{* *}$ & 1 & $0.9253^{* *}$ \\
Totox value & $-0.9443^{* *}$ & $-0.8904^{* *}$ & $-0.7761^{* *}$ & $0.9967^{* *}$ & $0.9253^{* *}$ & 1 \\
\hline
\end{tabular}

**Values are different from 0 with a significance level alpha $(\mathrm{P}=0.01)$. The number of replicates performed to determine the values of each variable was $3(n=3)$

of lipid oxidation which are responsible for the rancid odor and taste of the Italian Taralli (ringshape, breadsticks contained $20 \%$ vegetable oil) are the same products that are evaluated with the $p$-anisidine test.

\section{CONCLUSIONS}

Ginseng extract significantly increased the oxidative stability of breadsticks up to 55 days at room temperature. Breadstick samples prepared with $1 \%$ ginseng extract were significantly well accepted $(\mathrm{P}<0.05)$ in terms of odor, taste and texture compared to BHT samples.

\section{ACKNOWLEDGMENT}

The authors wish to thank Prof. Samy Mohamed Galal, Professor in the Food Science Department, Faculty of Agriculture, Cairo University for his advice and support during the investigation.

\section{REFERENCES}

Abdel-Aal EM, Rabalski I. 2013. Effect of baking on free and bound phenolic acids in wholegrain bakery products. J. Cereal Sci. 57, 312-318. https:// doi.org/10.1016/j.jcs.2012.12.001

Alamprese C, Cappa C, Ratti S, Limbo S, Signorelli M, Fessas D, Lucisano M. 2017. Shelf life extension of whole-wheat breadsticks: Formulation and packaging strategies. Food Chem. 230, 532-539. https://doi.org/10.1016/j.foodchem.2017.03.092

AOCS. 2009. Official Methods and Recommended Practices of the American Oil Chemists' Society, $6^{\text {th }}$ edn. AOCS Press, Champaign, IL.
Arnous A, Makris DP, Kefalas P. 2002. Correlation of pigment and flavanol content with antioxidant properties in selected aged regional wines from Greece. J. Food Compos. Anal. 15, 655-665. https://doi.org/10.1006/jfca.2002.1070

Barbieri S, Bendini A, Balestra F, Palagano R, Rocculi P, Gallina Toschi T. 2018. Sensory and instrumental study of Taralli, a typical Italian bakery product. Euro. Food Res. Technol. 244, 73-82. https://doi.org/10.1007/s00217-017-2937-8

Bhat NA, Wani IA, Hamdani AM, Gani A. 2019. Effect of extrusion on the physicochemical and antioxidant properties of value added snacks from whole wheat (Triticum aestivum L.) flour. Food Chem. 276, 22-32. https://doi.org/10.1016/j. foodchem.2018.09.170

Calligaris S, Pieve SD, Kravina G, Manzocco L, Nicoli CM. 2008. Shelf life prediction of bread sticks using oxidation indices: A validation study. J. Food Sci. 73, E51-E56. https://doi. org/10.1016/j.foodres.2018.03.034

Caruso MC, Galgano F, Colangelo MA, Condelli N, Scarpa T, Tolve R, Favati F. 2017. Evaluation of the oxidative stability of bakery products by OXITEST method and sensory analysis. Eur. Food Res. Technol. 243, 1183-1191. https://doi. org/10.1007/s00217-016-2831-9

Chen Y, Zhao Z, Chen H, Brand E, Yi T, Qin M, Liang Z. 2017. Determination of ginsenosides in Asian and American ginsengs by liquid chromatography-quadrupole/time-of-flight MS: assessing variations based on morphological characteristics. J. Ginseng Res. 41, 10-22. https://doi. org/10.1016/j.jgr.2015.12.004 
Chien YS, Yu ZR, Koo M, Wang BJ. 2016. Supercritical fluid extractive fractionation: Study of the antioxidant activities of Panax ginseng. Sep. Sci. Technol. 51, 954-960. https://doi.org/10.1080/01 496395.2016.1140202

CODEX STAN. 321-2015. 2015. Standard for ginseng products.

Daoud S, Bou-maroun E, Dujourdy L, Waschatko G, Billecke N, Cayot P. 2019. Fast and direct analysis of oxidation levels of oil-in-water emulsions using ATR-FTIR. Food Chem. 293, 307-314. https://doi.org/10.1016/j.foodchem.2019.05.005

Difonzo G, Pasqualone A, Silletti R, Cosmai L, Summo C, Paradiso VM, Caponio F. 2018. Use of olive leaf extract to reduce lipid oxidation of baked snacks. Food Res. Int. 108, 48-56. https:// doi.org/10.1016/j.foodres.2018.03.034

Esfarjani F, Khoshtinat K, Zargaraan A, Mohammadi-Nasrabadi F, Salmani Y, Saghafi Z, Hosseini H, Bahmaei M. 2019. Evaluating the rancidity and quality of discarded oils in fast food restaurants. Food Sci. Nutr. 7, 2302-2311. https://doi. org/10.1002/fsn3.1072

Hwang CR, Lee SH, Jang GY, Hwang IG, Kim HY, Woo KS, Lee J, Jeong HS. 2014. Changes in ginsenoside compositions and antioxidant activities of hydroponic-cultured ginseng roots and leaves with heating temperature. J. Ginseng Res. 38, 180-186. https://doi.org/10.1016/j.jgr.2014.02.002

Klaypradit W, Kerdpiboon S, Singh RK. 2011. Application of artificial neural networks to predict the oxidation of menhaden fish oil obtained from Fourier transform infrared spectroscopy method. Food Bioproc. Tech. 4, 475-480. https://doi. org/10.1007/s11947-010-0386-5

Kobus-Cisowska J, Flaczyk E, Rudzińska M, Kmiecik D. 2014. Antioxidant properties of extracts from Ginkgo biloba leaves in meatballs. Meat Sci. 97, 174-180. https://doi 10.1016/j.meatsci.2014.01.011

Kozłowska M, Zbikowska A, Szpicer A, Połtorak A. 2019. Oxidative stability of lipid fractions of sponge-fat cakes after green tea extracts application. J. Food Sci. Technol. 56, 2628-2638. https://doi.org/10.1007/s13197-019-03750-5

Lan W, Che X, Xu Q, Wang T, Du R, Xie J, Hou $\mathrm{M}$, Lei H. 2018. Sensory and chemical assessment of silver pomfret (Pampus argen- teus) treated with Ginkgo biloba leaf extract treatment during storage in ice. Aquaculture Fisheries 3, 30-37. https://doi.org/10.1016/j. aaf.2017.09.003

Li W, Fitzloff JF. 2002. HPLC determination of ginsenosides content in ginseng dietary supplements using ultraviolet detection. J. Liq. Chromatogr. Relat. Technol. 25, 2485-2500. https://doi. org/10.1081/JLC-120014269

Mustac NC, Novotni D, Habu M, Drakula S, Nanjara L, Voucko B, Benkovic M, Curic D. 2020. Storage stability, micronisation, and application of nutrient-dense fraction of proso millet bran in gluten-free bread. J. Cereal Sci. 91, 102864. https://doi.org/10.1016/j.jcs.2019.102864

Niccolai A, Venturi M, Galli V, Pini N, Rodolfi L, Biondi N, D'Ottavio M, Batista AP, Raymundo A, Granchi L, Tredici MR. 2019. Development of new microalgae based sourdough "crostini": functional effects of Arthrospira platensis (spirulina) addition. Sci. Rep. 9, 19433. https://doi. org/10.1038/s41598-019-55840-1

Park H, Lee M, Kim KT, Park E, Paik HD. 2018. Antioxidant and antigenotoxic effect of dairy products supplemented with red ginseng extract. J. Dairy Sci. 101, 8702-8710. https://doi. org/10.3168/jds.2018-14690

Pereira E, Barros L, Ferreira ICFR. 2013. Chemical characterization of Ginkgo biloba L. and antioxidant properties of its extracts and dietary supplements. Ind. Crops Prod. 51, 244-248. https://doi. org/10.1016/j.indcrop.2013.09.011

Reis SF, Abu-Ghannam N. 2014. Antioxidant capacity, arabinoxylans content and in vitro glycaemic index of cereal-based snacks incorporated with brewer's spent grain. LWT-Food Sci. Technol. 55, 269-277.

Riaz M, Rahman NU, Zia-Ul-Haq M, Jaffar HZE, Manea R. 2019. Ginseng: A dietary supplement as immune-modulator in various diseases. Trends Food Sci. Technol. 83, 12-30. https://doi. org/10.1016/j.tifs.2018.11.008

Sati P, Dhyani P, Bhatt ID, Pandey A. 2019. Ginkgo biloba flavonoid glycosides in antimicrobial perspective with reference to extraction method. $J$. Tradit. Complement. Med. 9, 15-23. https://doi. org/10.1016/j.jtcme.2017.10.003

Thanushree MP, Sudha ML, Crassina K. 2017. Lotus (Nelumbo nucifera) rhizome powder as a novel 
ingredient in bread sticks: rheological characteristics and nutrient composition. J. Food Meas. Charact. 11, 1795-1803. https://doi.org/10.1007/ s11694-017-9561-y

Wang HY, Zhang YQ. 2019. The main active constituents and detoxification process of Ginkgo biloba seeds and their potential use in functional health foods. $\mid J$. Food Compost. Anal. 83, 103247. https://doi.org/10.1016/j.jfca.2019.103247

Wang X, Xie K, Zhuang H, Ye R, Fang Z, Feng T. 2015. Volatile flavor compounds, total polyphenolic contents and antioxidant activities of a China Ginkgo wine. Food Chem. 182, 41-46. https:// doi.org/10.1016/j.foodchem.2015.02.120 